\title{
PAGES Lake Drilling Task Force (LDTF)
}

The PAGES Lake Drilling Task Force (LDTF) has been active for three and a half years now, and has yet to drill a lake (except for Baikal, where the Baikal Drilling Project (BDP) was begun earlier). However, slow but steady progress has been made, and optimism is still high.

A formal feasibility study of drilling in large lakes has been completed. This study was carried out by a consortium of commercial companies, funded by the International Continental Scientific Drilling Program (ICDP), and presented to the LDTF in April, 1998. It was targeted at long $(800+\mathrm{m})$ cores from the largest, deepest lakes. The recommended equipment consists of an oil-field drill rig mounted on a large, modular barge (made up of $40 \times 8 \times 8$-ft modified shipping containers), which would incorporate dynamic positioning and heave compensation. This system would certainly accomplish our goals, but is quite expensive: estimated costs for drilling operations on a single large lake are on the order of 3-4 million USD. It is clear, however, that obtaining 1000 $\mathrm{m}$ cores in large, deep lakes will require this type of investment.

At the suggestion of some of the managers at US NSF who are focused on paleoclimate records (and less interested in sediments more than a few glacial cycles old), smaller-scale possibilities have begun to be explored. This concept was reinforced by discussions at an ICDP-funded workshop in May, 1998, to plan drilling at Lake Titicaca. Shortly afterward, a group called DOSECC (Drilling, Observation, and Sampling of the Earth's Continental Crust) stepped forward with an offer to help. DOSECC is a private, non-profit corporation funded by US NSF (similar to the Joint Oceanographic Institution (JOI) for the oceanographic community) to assist with U.S. continental drilling activities. DOSECC offered the services of its engineers to help design a smaller lake drilling system. They also offered to operate the system at cost (much lower than commercial costs), and to own, store, and maintain it, once initially acquired, for future drilling operations. These offers were viewed as significant advances of our plans and needs, so we proceeded to try to take advantage of them.

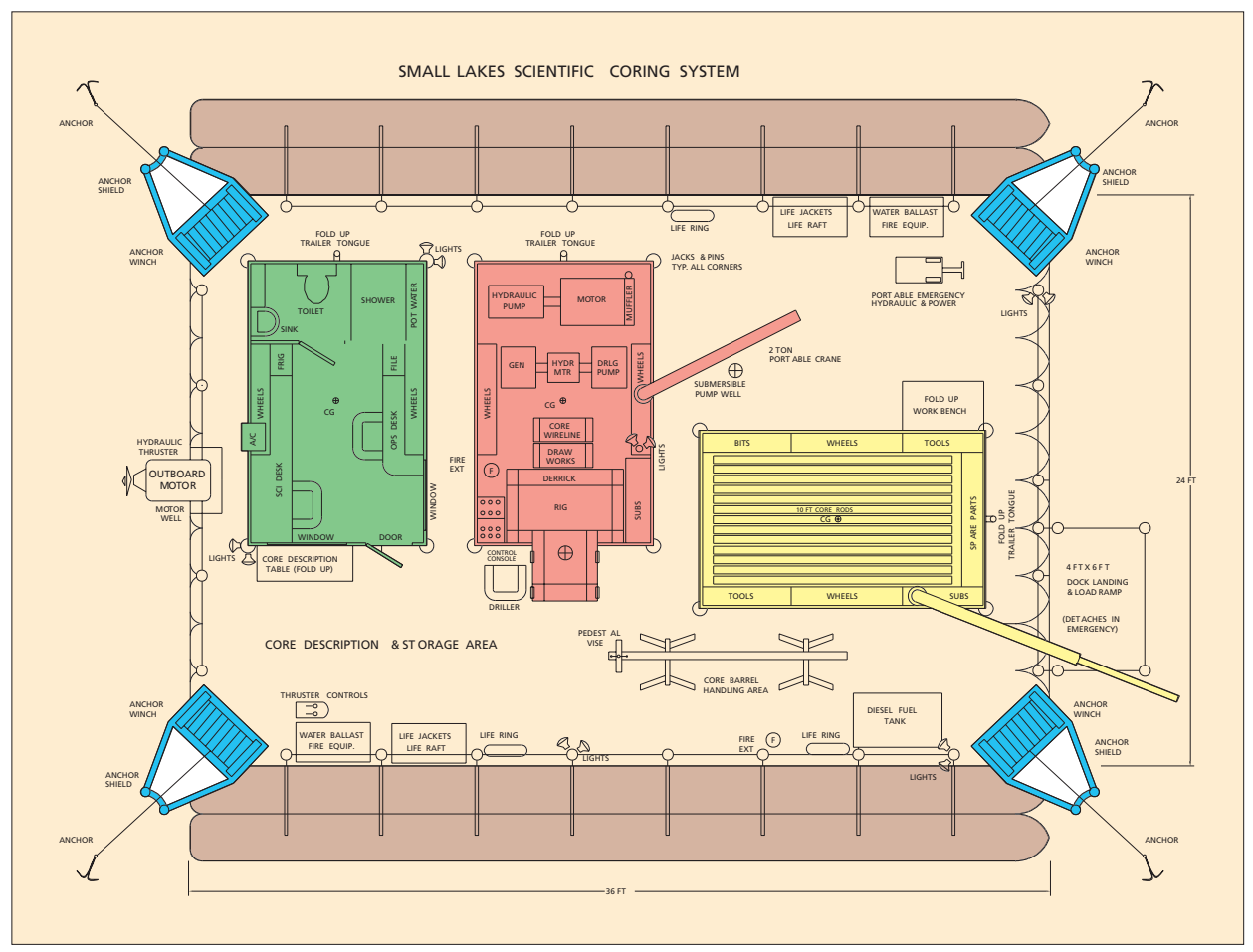

Preliminary drawing of the raft for the smaller drilling system

The initial design criteria were cores as much as $200 \mathrm{~m}$ long in as much as $200 \mathrm{~m}$ of water. It is likely that this is sufficient to address most (but not all) paleoclimate issues in most (but not all) lakes. The design produced by DOSECC, and discussed at a small meeting in Minneapolis in October, 1998, calls for a mining-style drill rig mounted on a $24 \times 36$ foot raft supported by marine industrialgrade inflatable pontoons. Further discussions revealed that the system could be equipped with a drill rig that would have a total drill-string length of up to $800 \mathrm{~m}$ and still obtain cores of standard Ocean Drilling Program (ODP) diameter. This system could also be mounted on a larger barge for drilling operations in lakes that are too large for the anchored, inflatable-pontoon-based raft.

The smaller system is viewed as complementary to the larger drilling system, providing additional options at more modest costs. In no way can it serve as a replacement for the original larger system, which still would be required for drilling deep cores in the largest lakes. An intermediate option would be to mount the smaller drill rig on a more substantial barge and drill as deep as the $800 \mathrm{~m}$ total-drill-string limit would allow.

It was suggested that the smaller drilling system be constructed near
DOSECC engineering headquarters in Salt Lake City and tested in nearby Great Salt Lake and Bear Lake, which have excellent scientific justifications for drilling. Despite the excellent scientific reasons for drilling in Great Salt and Bear Lakes, this operation would still be focused on design, acquisition, and testing of the system, and would not be intended as a new drilling initiative in competition with the lake drilling projects tentatively approved by ICDP (IDEAL lakes [Edward, Malawi, and Tanganyika], Lake Titicaca, and Qinghai Lake).

Representatives of groups with research experience in Great Salt Lake and Bear Lake met in mid-December, 1998, to draft a proposal that would be submitted to both ICDP and US NSF. The groups include the Universities of Arizona, Minnesota, Kansas State, and Utah, as well as the U.S. Geological Survey. A variety of scientific issues that could be addressed by drilling were discussed, including paleoclimate (over the last 150-450 ka), neotectonics, structural geology, and basin/biological evolution. The amount of drilling associated with each of these objectives varies, so the associated costs were modularized in the proposal. In all cases, cores obtained in the testing operation would be subjected to basic processing and archiving (split- 


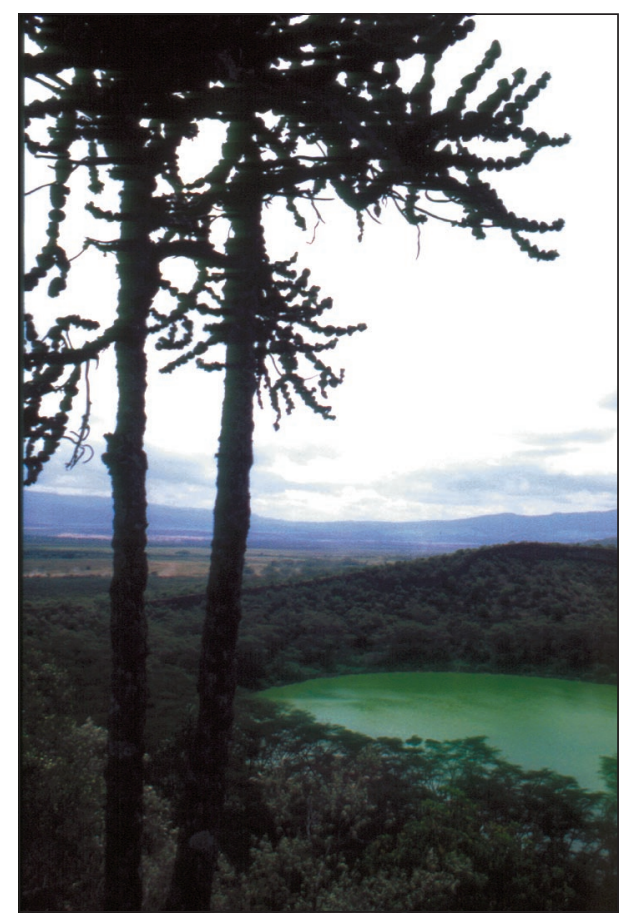

Lake Sonachi, Eastern Rift Valley, Kenya (Photo: Dirk Verschuren).

LDTF, continued from previous page

ting, description, logging, and reconnaissance dating and compositional analyses). From there, the cores would be available for future detailed analytical projects. The acquisition and construction costs of the system are about 0.7 million USD. Minimum costs for testdrilling operations and basic core processing are about 0.3 million USD for 300-400 m of core (paleoclimate or neotectonic issues only). For the $2500 \mathrm{~m}$ of core that would be necessary to address all of the scientific issues, the drillingprocessing costs would be about 0.5 million. Total cost of the acquisition and testing project would therefore range between 1.0 and 1.2+ million USD.

We have been working for almost four years to develop a functional lakedrilling system. We believe that the proposed drilling system would provide an opportunity to address many of the priorities of ICDP and PAGES, including those of previously reviewed ICDP lake-drilling projects. Much depends on the fate of this latest proposal in the review process at ICDP and NSF over the next few months (January-April, 1999). Stay tuned.

\section{Steven M. Colman}

U.S. Geological Survey, Woods Hole MA, USA scolman@usgs.gov

http://woodshole.er.usgs.gov/ scolman/

\section{PEP III African Crater Lakes Workshop}

\author{
Gent, Belgium, October 10-11 1998
}

Unraveling the climatic history of Africa and the Near East during the past 2000 years remains one of the major challenges in paleoclimate research, and sediment records from crater lakes are among the most valuable sources of information on this history. However, apart from the unique biology and distinct hydrogeological settings of the tropical and subtropical crater lakes dotting the southern half of the PEP III transect, their study also involves issues of access, organization, and scientific infrastructure that are quite different from the situation in Europe and add to the challenge of obtaining high-quality climate-proxy records from them (see PAGES Newsletter 97-2). The 1996 PEP III strategy meeting in Bierville (see PAGES Report 97-2) stressed the urgent need to redress the current geographic imbalance of paleoclimatic information within the PEP III transect, and recommended prioritization of a research initiative focusing specifically on highresolution, PAGES Time Stream 1 paleoclimate reconstruction using sediment records from crater lakes and other small lakes in Africa and the Near East.

The African Crater Lakes workshop in Gent brought together a group of leading paleolimnologists currently active in Africa and the Near East, PAGES representatives, and specialists in data acquisition and management who could take on the function of a thematic working group to promote, guide and coordinate future lake-based, late Holocene paleoclimate research following PAGES guidelines with respect to time resolution, chronological control, climate-proxy calibration, and data management.

\section{Regional data synthesis}

Despite the large number of crater lakes and other small natural water bodies across Africa and the Near East, only a small subset of them are likely to have accumulated a continuous record of past environmental change resolvable at subannual to decadal time scales. A major objective of the meeting was to identify and rank specific study sites according to their potential for paleoclimate reconstruction. The main part of the meeting therefore comprised region-by-region summaries of the present status of Time Stream 1 paleoclimate research in Africa and the Near East, and comparative evaluation of sites according to their potential to preserve a continuous sediment record of late-Holocene hydro-climatic variability. The geographical hub of the southern PEP III transect is the East African Rift, within which key areas include central Ethiopia (data summarised by H. Lamb and L. Carvalho), central Kenya (D. Verschuren), and southwest Tanzania (D. Williamson, P. Barker). Other important clusters of crater lakes, so far less well studied paleolimnologically, exist in western Uganda (D. Verschuren), Cameroon, and Madagascar (F. Gasse). Important complementary archives exist in the form of small high-altitude headwater lakes, in some cases pro-glacial, and recent work on $\mathrm{Mt}$. Kenya was described by K. Holmgren (on behalf of W. Karlén) and P. Barker. The intense hydrological deficit in northeastern Africa means that few lakes of any kind are available for study, making the handful of extant crater lakes in northern Sudan prime study targets (S. Kroepelin). A greater density of crater lakes exists adjacent to the Jordan Rift and in central and eastern Turkey (N. Roberts). Subtropical regions at the southern end of the PEP III transect seem to have few lake sites suitable for highresolution paleoclimate research (L. Scott), and are likely to be better served via other climate-proxy archives such as speleothem records (K. Holmgren).

\section{Research Questions}

The working group identified two principal categories of research questions: (1) fundamental questions about the history and causes of climatic variability, and (2) methodological questions about the reliability of sedimentary proxy records as the source of information on that climatic variability.

(1) The primary goal of Time Stream 1 paleoclimate research on African crater and other small lakes is to document the temporal patterns and spatial coherence of past climatic change with a quality of proxy data and chronological control that permits evaluation of possible causative mechanisms over a hierarchy of time- 